\title{
Neuro-discriminate Model for the Forecasting of Changes of Companies Financial Standings on the Basis of Self-organizing Maps
}

\author{
Egidijus Merkevičius ${ }^{1}$, Gintautas Garšva ${ }^{1,2,3}$, and Rimvydas Simutis ${ }^{1}$ \\ ${ }^{1}$ Department of Informatics, Kaunas Faculty of Humanities, Vilnius University \\ Muitinès st. 8, LT- 44280 Kaunas, Lithuania \\ ${ }^{2}$ Department of Information Systems, Kaunas University of Technology, \\ Studentu 50, LT-51368 Kaunas, Lithuania \\ ${ }^{3}$ Department of Informatics, Engineering and Biomechanics, Lithuanian Academy of \\ Physical Education, \\ Sporto 6, LT-44221 Kaunas, Lithuania \\ \{egidijus.merkevicius, gintautas.garsva, \\ rimvydas.simutis\} avukhf. It
}

\begin{abstract}
This article presents the way how creditor can predict the trends of debtors financial standing. We propose the model for forecasting changes of financial standings. Model is based on the Self-organizing maps as a tool for prediction, grouping and visualization of large amount of data. Inputs for training of SOM are financial ratios calculated according any discriminate bankruptcy model. Supervised neural network lets automatically increase accuracy of performance via changing of weights of ratios.
\end{abstract}

Keywords: self-organizing maps, Z-score, bankruptcy, prediction, bankruptcy class, multivariate discriminate model, Altman, Zmijewski, feed-forward neural network, model.

\section{Introduction}

Bankruptcy is a process which results reorganization of the company in order to repay debts and fulfill other liabilities. Close monitoring of financial standing of the company is very important in order to prevent possible bankruptcy.

Model forecasting changes in financial standing is presented in this article. The fundamental bankruptcy models (Altman, Zmijewski etc.), supervised and unsupervised artificial neural networks are used as the base in this model. The concept of the model is universal - any of discriminate bankruptcy model can be used in order to describe the company by one meaning.

Related works are presented in the first part of the article. The methodology of the model is described in the second part. Third part includes description and results of testing of the model with the actual financial data. 


\section{Related Work}

Bankruptcy is described as inability or impairment of ability of an individual or organization to pay their creditors, in other words - default. One of the most important tasks of the creditors is to manage the credit risk making forecast of changes in financial standing. The early history of research attempts to classify and predict bankruptcy is well documented in [1],[7]. Altman [2], Zmijewski, [16], Ohlson [10], Shumway [14] and other authors are the first and fundamental creators of bankruptcy models. The key-point of these models is to determine most important indicators (ratios) and their weights in discriminate or logistic function. A detailed description of the SOM method is presented in [9].

During the past 15 years investigations in area of SOM applications to financial analysis have been done. Doebeck described and analyzed most cases in [5]. Martindel-Prio and Serrano-Cinca generated SOM's of Spanish banks and subdivided those banks into two large groups, the configuration of banks allowed establishing root causes of the banking crisis [11].

Based on Kiviluoto's study [8], through visual exploration one can see the distribution of important indicators (i.e. bankruptcy) on the map.

The following authors have estimated only historical and current financial data of the companies and afterwards they have interpreted it for forecasting bankrupt of those companies. In this paper, we suggest generating SOM as one that could be applied for forecasting of bankruptcy classes for other than trained companies.

\section{Methodology}

In this section we present Neuro-discriminate model for forecasting of changes of companies financial standings on the basis of Self-organizing maps (further - Model). The Model includes various methods - multivariate discriminate analysis, selforganizing maps, feed-forward supervised neural network, combination of which makes original model of forecasting. These methods [2], [16], [9], [1] used in the Model are original with no major adjustments, so they are not presented.

The main concept of the Model is presented in figure 1.

Description of the Model concept:

1. On the basis of bankruptcy models changes of companies financial standing are determined ( 0 - negative changes, 1 - positive changes);

2. The components of discriminate bankruptcy model are used for training of unsupervised neural network and generating SOM. Testing of accuracy of the SOM is executed via calculation of corresponding nodes between training and testing data.

3. The accuracy of forecasting is improved via changing of weights. Feedforward neural network is used in the Model as a tool for changing of weights where inputs are test data and targets are outputs of trained SOM. 


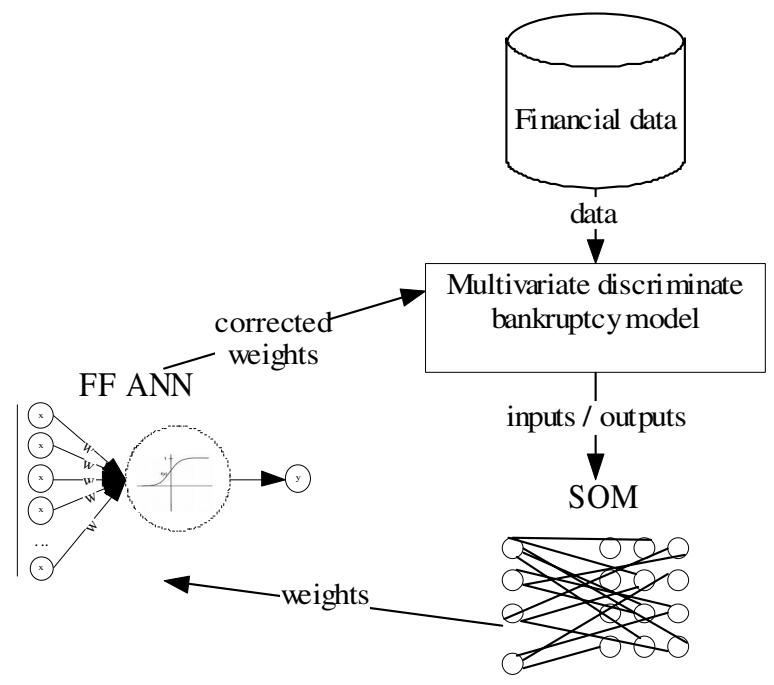

Fig. 1. The concept of the Model

The detailed algorithm of the Model is visualized in figure 2.

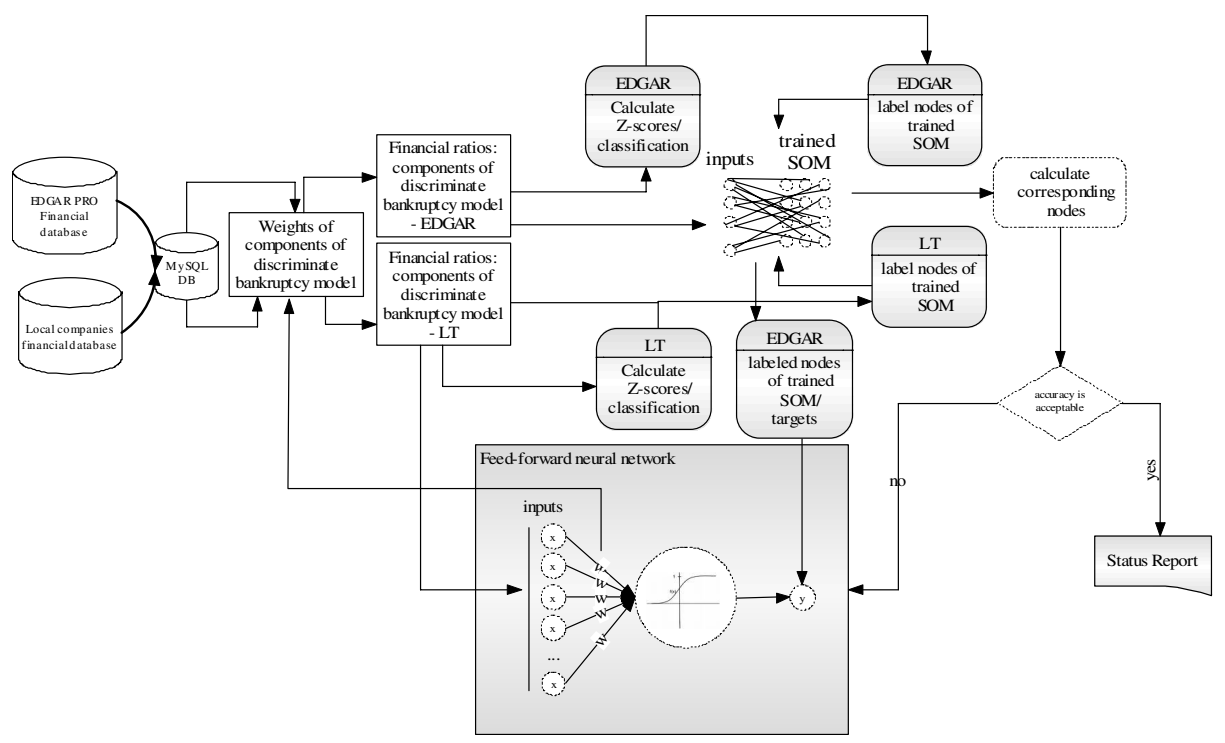

Fig. 2. Algorithm of proposed Model and methodology of weights adoption

The main steps of the algorithm are as follows:

1. On the basis of financial statements of the companies, taken from EDGAR PRO Online database (further related data is named EDGAR)[6], the 
financial variables (ratios) and the bankruptcy scores (further named Z-scores) are calculated and converted to bankruptcy classes based on Z-scores changes during two years (0-negative changes, 1-positive changes). The same calculations are made with data, taken from other financial sources, for example, financial statements of Lithuanian companies (further related data is named LT), assigning bankruptcy classes (0-negative changes, 1-positive changes) in the same way as described above.

2. Data preprocessing is executed. The process consists of normalizing data set, selecting map structure and the topology, setting other options like data filter, delay etc.

3. The SOM is generated on the basis of EDGAR data. The Inputs of SOM are the Z-Score variables and the labels are bankruptcy classes.

4. The generated SOM is labeled with the bankruptcy classes of LT companies.

5. Labeled units of the trained SOM are compared with the same units labeled with LT bankruptcy classes. Corresponding units are calculated. If the number of corresponding EDGAR and LT labels which are located on the same SOM map unit number (accuracy of prediction) is acceptable, then status report is generated, otherwise changing of weights with the feedforward neural network (further - FF ANN) starts.

6. The attempt to increase corresponding labels is made in order to create such a map structure in which the amount of unit numbers has the biggest corresponding label number. For this goal we have used FF ANN, where inputs are the ratios of LT calculated as bankruptcy discriminate model with no weights. The targets of the ANN are units of SOM labels which belong to correspondent LT data. The initial weights of ANN are the original weights of bankruptcy discriminate model. As a result we have changed weights.

7. The weights of original discriminate bankruptcy model are updated with changed weights.

8. Next iteration of presented algorithm starts (1-7 steps). When the performance of the prediction doesn't rapidly change the algorithm has stopped.

The results of this algorithm are as follows:

1. New SOM with a certain prediction percentage and good visualization of large amount of data;

2. Original way how to use different financial database in the same bankruptcy model.

3. New multivariate discriminator model that is based on the original discriminate bankruptcy model with corrected weight variables.

4. Automatic tool to update original weights according to accuracy of prediction - FF ANN.

Result of prediction is the most important information for creditor showing the trend of a company (positive or negative changes of financial standing of company). 


\section{Results of Testing}

In this section we have presented the results of Model testing.

The testing of proposed Model has been executed using two real financial datasets: companies from NASDAQ list, (further - TRAINDATA) loaded from EDGAR PRO Online database and a dataset of Lithuanian company's financial statements (TESTDATA) presented by one of the Lithuanian banks.

The basis for generating the SOM is TRAINDATA. Calculated bankruptcy ratios are based on the original discriminate bankruptcy model by Zmijewski [16]. The ratios are used as inputs and changes of Z-Scores during two years are used as labels for the identification of units in the SOM.

Table 1. Characteristics of financial datasets

\begin{tabular}{|l|l|l|}
\hline Dataset & TRAINDATA & TESTDATA \\
\hline Taken from & $\begin{array}{l}\text { EDGAR PRO Online Database } \\
\text { free trial) }\end{array}$ & $\begin{array}{l}\text { Database of Lithuanian } \\
\text { bank. }\end{array}$ \\
\hline Period of financial data & 7 periods consecutively & $2003-2004$ \\
\hline Amount of companies & 9364 & 776 \\
\hline Count of records & 56184 & 776 \\
\hline $\begin{array}{l}\text { Count of records after } \\
\text { elimination of missing } \\
\text { data }\end{array}$ & 46353 & 767 \\
\hline $\begin{array}{l}\text { Number of inputs } \\
\text { (attributes) }\end{array}$ & \multicolumn{1}{|c|}{6} \\
\hline $\begin{array}{l}\text { Risk classes of } \\
\text { bankruptcy } \\
\text { first period then the risk class is determined as 0, otherwise } \\
\text { firs } \\
1 .\end{array}$ \\
\hline
\end{tabular}

The SOM was trained using the SOM Toolbox for Matlab package [15]. Changing of weights with FF ANN has been executed using NNSISID Toolbox for Matlab [13]. The testing process was as follows:

1. Getting data from financial sources and putting them to the MySQL database.

2. Filtering missing data.

3. Calculating Z-scores; assigning of the risk classes.

4. Dividing TRAIN data into two subsets: training and testing data with ratio 70:30.

5. Preprocessing of training data: normalizing of data set, selecting structure of map and topology, setting of other options like data filter, delay etc.

6. Executing algorithm which is described in the section 3 while accuracy of corresponding nodes between TRAINDATA and TESTDATA achieves desirable result.

In the figure 3 is presented the run of testing. 


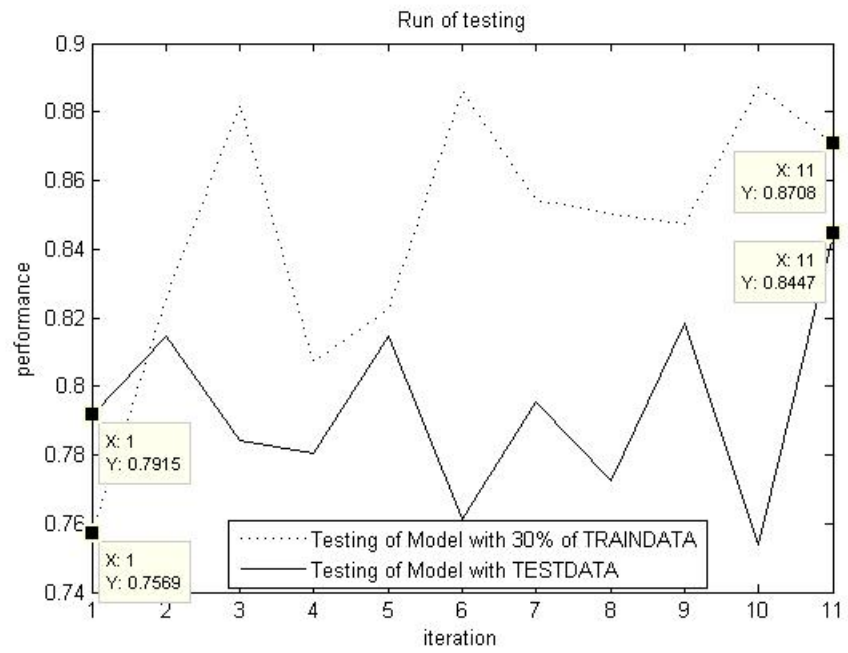

Fig. 3. Run of increase of Model performance

Figure 3 shows rapidly increase of Model performance: testing on the basis of original weights with $30 \%$ of TRAINDATA accuracy of prediction seeks $75.69 \%$, while testing with TESTDATA accuracy of prediction seeks $79.15 \%$; after changing of weights on the 11 step of cycle the accuracy of prediction seeks respectively $87.08 \%$ and $84.47 \%$. The number of iterations is related with 8 step of the algorithm, i.e. when the performance of the prediction doesn't rapidly change the algorithm has stopped.

Table 2 presents Performance matrix of TESTDATA.

Table 2. Performance matrix of TESTDATA

\begin{tabular}{|c|c|c|c|}
\hline \multicolumn{4}{|c|}{ Actual vs Predicted (Performance Matrix) } \\
\hline & \multicolumn{3}{|c|}{ Predicted (by model) } \\
\hline & 0 & 1 & Total (units) \\
\hline Actual $0(\%)$ & 73.47 & 26.53 & 98 \\
\hline Actual $1(\%)$ & 9.03 & 90.96 & 166 \\
\hline \multicolumn{3}{|c|}{ Total (\%) } & $84.47 \%$ \\
\hline
\end{tabular}

Table 3 presents comparison of importance of ratios in discriminate bankruptcy model before and after changing of weights.

The highest impact on results has Total liabilities/Total assets ratio and Net income/Total assets ratio. Changing of weights allows seek the highest accuracy of bankruptcy prediction. 
Table 3. Changes of variables weights before and after the cycle

\begin{tabular}{|l|c|r|r|}
\hline Name & $\begin{array}{c}\text { Variables (X0-first period, X1- } \\
\text { second period) }\end{array}$ & $\begin{array}{r}\text { Weight } \\
\text { before }\end{array}$ & Weight after \\
\hline no-ratio weight & X0_1 & $-4,336$ & $-4,336$ \\
\hline Net income/Total assets & X0_2 & $-4,513$ & $-5,834$ \\
\hline Total liabilities/Total assets & X0_3 & 5,679 & 5,255 \\
\hline S.-t. assets/ S.-t. liabilities & X0_4 & 0,004 & $-0,207$ \\
\hline no-ratio weight & X1_1 & $-4,336$ & $-4,336$ \\
\hline Net income/Total assets & X1_2 & $-4,513$ & $-4,545$ \\
\hline Total liabilities/Total assets & X1_3 & 5,679 & 4,617 \\
\hline S.-t. assets/ S.-t. liabilities & X1_4 & 0,004 & $-0,180$ \\
\hline $\begin{array}{l}\text { Performance of bankruptcy } \\
\text { prediction (\%) }\end{array}$ & & $\mathbf{7 9 . 1 5 \%}$ & $\mathbf{8 4 . 4 7 \%}$ \\
\hline
\end{tabular}

\section{Conclusions}

- The presented Neuro-discriminate model for forecasting of changes of companies financial standings on the basis of Self-organizing maps also includes multivariate discriminate analysis of bankruptcy and feed-forward supervised neural network; combination of these methods makes original model suitable for forecasting.

- The other authors which were studied capabilities of SOM in the areas of bankruptcy have estimated only historical and current financial data of the companies and afterwards they have interpreted it for forecasting bankrupt of those companies. We suggest generating SOM as one that could be applied for forecasting of bankruptcy classes for other than trained companies.

- The presented model works well with real world data, the tests of the model with presented datasets showed accuracy of prediction with more than $84 \%$ performance.

- Methodology of presented model is flexible to adopt every datasets because rules and steps of methodology algorithm are universal.

- Changing of weights with supervised neural network allows seek the highest accuracy of bankruptcy prediction.

- Result of prediction is the most important information for creditor showing the trend of a company (positive or negative changes of financial standing of company).

\section{References}

1. Atiya.: Bankruptcy prediction for credit risk using neural networks: a survey and new results. IEEE Transactions on Neural Networks, Vol. 12, No. 4, (2001) 929-935

2. Altman, E.: Financial Ratios, Discrimination Analysis and the Prediction of Corporate Bankruptcy. Journal of Finance, (1968) 
3. Altman. E.: Predicting Financial Distress of Companies: Revisiting the Z-Score and ZETA ${ }^{\circledR}$ Models. (working paper at http://pages.stern.nyu.edu/ ealtman/Zscores.pdf) (2000)

4. Deboeck, G.: Financial Applications of Self-Organizing Maps. American Heuristics Electronic Newsletter, Jan, (1998)

5. Deboeck, G.: Self-Organizing Maps Facilitate Knowledge Discovery In Finance. Financial Engineering News, (1998)

6. EDGAR Online, Inc. http://pro.edgar-online.com (1995-2006)

7. Galindo, J., Tamayo, P.: Credit Risk Assessment Using Statistical and Machine Learning: Basic Methodology and Risk Modeling Applications. Computational Economics. (2000), Vol 15

8. Kiviluoto, K.: Predicting bankruptcies with the self-organizing map. Neurocomputing, Vol. 21, (1998),191-201

9. Kohonen, T.: The Self-Organizing Map. Proceedings of the IEEE, 78:1464-1480

10. Ohlson, J. A.: Financial Ratios and the Probabilistic Prediction of Bankruptcy. Journal of Accounting Research (Spring). (1980), 109-131

11. Martin-del-Prio, K., Serrano-Cinca, Self-Organizing Neural Network: The Financial State of Spanish Companies. In Neural Networks in Finance and Investing. Using Artificial Intelligence to Improve Real-World Performance. R.Trippi, E.Turban, Eds. Probus Publishing, (1993), 341-357

12. Merkevičius, E., Garšva, G., Girdzijauskas, S.: A Hybrid SOM-Altman Model for Bankruptcy Prediction. International Conference on Computational Science (4), Lecture Notes in Computer Science, 3994, 364-371, (2006), ISSN 0302-9743

13. Nørgaard, M.: Neural Network Based System Identification Toolbox Version 2. Technical Report 00-E-891, Department of Automation Technical University of Denmark. (2000). http://kalman.iau.dtu.dk/research/control/nnsysid.html

14. Shumway, T.: Forecasting Bankruptcy More Accurately: A Simple Hazard Model, Journal of Business, Vol. 74, No. 1 (2001), 101-124

15. Vesanto, J., Himberg, J., Alhoniemi, E., Parhankangas, J.: SOM toolbox for Matlab 5, Technical report A57 (2000), Helsinki University of Technology, Finland

16. Zmijewski, M. E.: Methodological Issues Related to the Estimation of Financial Distress Prediction Models. Journal of Accounting Research 24 (Supplement): (1984) 59-82 